\title{
Welfare and Trade Effects of International Environmental Agreements
}

\author{
Catia Montagna $^{2} \cdot$ Avanti Nisha Pinto $^{1} \cdot$ Nikolaos Vlassis $^{2}$ (D)
}

Accepted: 6 May 2020 / Published online: 7 June 2020

(c) The Author(s) 2020

\begin{abstract}
We analyse the welfare effects of environmental policy arising from the formation of an international environmental agreement on the participating and non-participating countries and thus shed light on the potential incentives for a country to join such an agreement. Within a $N$-country $Q$-goods general equilibrium framework under free-trade conditions, we consider unilateral and cooperative policy settings and, within the latter, country-specific and fully harmonized policies within the agreement. A key result of the paper is the emergence of a negative relationship, arising from terms of trade effects, between the welfare changes of the participating and non-participating countries following the formation of the agreement. These however do not result in a zero sum welfare outcome for the world as a whole.
\end{abstract}

Keywords International environmental agreements · Environmental taxation · International trade $\cdot$ Pareto efficiency $\cdot$ Pareto improving reforms $\cdot$ Climate change

JEL Classification Q56 $\cdot \mathrm{H} 23 \cdot \mathrm{F} 18$

\section{Introduction}

Climate change and the trans-boundary nature of environmental pollutants have drawn the attention of academics and policymakers to the interaction between international trade and the environment and to the importance of internationally coordinated actions in addressing environmental concerns. Since the United Nations Conference on the Human Environment in 1972, environmental policy efforts globally have been geared towards finding potential

Nikolaos Vlassis

nvlassis@abdn.ac.uk

1 Brighton Business School, University of Brighton, Mithras House, Lewes Road, Brighton BN2 4AT, UK

2 Business School, Department of Economics, University of Aberdeen, Edward Wright Building, Dunbar Street, Aberdeen, Scotland AB24 3QY, UK 
solutions in a multilateral context-through international (IEA) or regional environmental agreements (REA). ${ }^{1}$

The extant theoretical literature suggests that countries may not be willing to adopt stricter environmental policy fearing other countries' free-riding behaviour and/or loss of competitiveness - as reflected by the pollution haven hypothesis. One strand of the environmental literature suggests that coordinated actions between governments, such as those resulting from the formation of environmental agreements, can address these incentive issues (see among others Baylis et al. 2014; Chua 2003). Against this background, it is important to shed light on the potential channels that may incentivise countries to join an environmental agreement.

In this paper, we conjecture that, by affecting the terms of trade, environmental policy can give rise to trade creation and diversion effects that will shape the welfare implications of, and the incentives to join, international environmental agreements for the participating and non-participating countries. To explore this conjecture, we develop a $N$-country $Q$-goods perfectly competitive general equilibrium international trade model in which a subset of countries form an environmental agreement. ${ }^{2}$ We assume pollution to be trans-boundary and arising from production activities and that governments can affect environmental quality by means of an emissions tax. The assumption of free-trade, consistent with WTO objectives, facilitates a clearer identification of the various welfare effects emerging solely from environmental policy.

Our results confirm that an important channel for the welfare impact of environmental agreements are terms-of-trade induced trade creation and diversion effects. A major contribution of the paper is to show that terms of trade effects are crucial to the emergence of a negative relationship between the changes in welfare of signatories and non-signatories countries - whereby a Pareto improving environmental policy reform for the former may be welfare reducing for the latter. We find however that the overall effects of a change in policy within the IEA do not result in a zero sum welfare outcome. Thus, our results suggest that countries participating in an IEA may be able to use their environmental policies to manipulate the terms of trade so as to mitigate the negative impact of stricter emission control on competitiveness that underpins the pollution haven effects of environmental policy commonly highlighted by the literature.

The literature addressing environmental policy coordination mainly deals with the characterisation of optimal (first and second best) environmental and/or trade policy (see, e.g., Copeland 1994; Neary 2006; Keen and Kotsogiannis 2014; Tsakiris et al. 2014) and policy reforms (Turunen-Red and Woodland 2004; Copeland 1994). The welfare consequences of policy reforms have mainly been analysed within a purely unilateral (e.g. Markusen 1975; Krutilla 1991; Copeland 1994; Hatzipanayotou et al. 2008; Michael and Hatzipanayotou 2013; Tsakiris et al. 2014, 2017) or a fully-cooperative (e.g. Keen and Kotsogiannis 2014; Kotsogiannis and Woodland 2013; Vlassis 2013) context. To the best of our knowledge, the case of partial cooperation among a subset of countries has not been studied within this framework.

\footnotetext{
1 The United Nations Environmental Programme (UNEP) (www.unep.org) defines Multilateral Environmental Agreements (MEAs) as international agreements between three or more countries (agreements between two countries are referred to as "bilateral agreements") on how to jointly address environmental problems of a cross-border nature. Mitchell (2003) surveys multilateral and bilateral environmental agreements to number approximately 700 and over 1000, respectively. Similarly, according to the IEA database (http://iea.uoregon.edu/) there are $1300 \mathrm{MEAs}$ and over 2200 bilateral agreements. The likely relatively higher homogeneity and the lower enforcement and coordination costs characterising smaller regions may explain the greater ease in forming smaller regional as opposed to larger environmental agreements.

${ }^{2}$ Here we are not concerned with the issue of coalition formation and stability (Finus 2003).
} 
Alongside the trade theoretic approach within which this paper is developed, a game theoretic approach has primarily focused on environmental agreements' behaviour-from their formation, to participation incentives, and to factors contributing to their effectiveness (for recent reviews of this literature see, among others, Finus and Caparros (2015) and Marrouch and Chaudhuri (2016)). ${ }^{3}$ More recently, Al Khourdajie and Finus (2020) focus on the role of trade instruments, in the form of Border Tax Adjustment (BCA), in offsetting countries' incentives to free ride in an IEA. In line with our results, this strand of the literature implies that terms of trade effects can potentially incentivise countries to join an IEA. While the game theoretic approach can study IEA behavioural aspects in a partially cooperative framework, it does not capture general equilibrium effects and is limited in its ability to characterise optimal policies and reforms.

The rest of the paper is organised as follows. Section 2 sets out the model. Section 3 derives and discusses the optimal unilateral and cooperative environmental policy in the absence and presence of an International Environmental Agreement. Section 4 determines the relationship between the welfare changes of the participating and non-participating countries. Section 5 concludes the paper.

\section{The Model}

We adopt a standard perfectly competitive general equilibrium international trade model characterised by $N$ large open economies each producing and trading $Q$ goods under conditions of free-trade. ${ }^{4}$ Pollution emissions are a by-product of production and are assumed to affect the representative consumer's welfare directly, whilst having no effect on the production capabilities of firms. ${ }^{5}$ Factors of production are assumed to be internationally immobile and inelastically supplied. In what follows, superscripts and subscripts refer to the country and partial derivatives, respectively.

The vector of world prices is denoted by $p$ and country $j$ 's $Q$-dimensional vector of emissions is denoted by $z^{j}$. Pollution is assumed to be trans-boundary; thus, global pollution is the sum of all countries' emissions:

$$
k=\sum_{j=1}^{N} \theta^{j \prime} z^{j},
$$

\footnotetext{
${ }_{3}^{3}$ Papers focusing on issues of enforcement and on the size of IEAs (Hoel 1992; Barrett 1994; Eichner and Pethig 2013) tend towards a pessimistic outlook about the stability of large IEAs. When IEA games include environmental or trade policy options (e.g., Eichner and Pethig 2015; Dong and Zhao 2009; Finus and Rundshagen 2000), the results regarding participation and cooperation are mixed. In addition, there is a significant portion of the game theory literature that highlights the role of trade sanctions in increasing the stability of cooperation among countries (e.g., Hoel and Schneider 1997; Carraro et al. 2006; Barrett 1995, 1997).

${ }^{4}$ The basic framework of analysis relies on that developed by Turunen-Red and Woodland (2004) and Keen and Kotsogiannis (2014). Our focus differs in that we consider partial cooperation, among a subset of countries, instead of full cooperation and we do not impose any restriction on trade - in line with WTO objectives (GATT article I and II). This allows us to analyse and isolate the effects of international environmental agreements on the welfare of both participating and non-participating countries.

${ }^{5}$ See Copeland (1994) and Keen and Kotsogiannis (2014).
} 
where the parameters in vector $\theta^{j}$ denote the perfect or partial trans-boundary nature of pollution. In general $\theta_{q}^{j} \leq 1$; for simplicity, and without loss of generality, we shall assume that $\theta_{q}^{j}=1$ for all $q \mathrm{~s}$ and let $\theta^{j}=i$, where $i$ represents the $N$-vector of $1 \mathrm{~s}$. Prime indicates transposition.

Country j's consumer preferences are described by the expenditure function:

$$
e^{j}\left(u^{j}, p, k\right)=\min _{x^{j}}\left\{p^{\prime} x^{j}: u^{j}\left(x^{j}, k\right) \geq \tilde{u}^{j}\right\},
$$

which represents the minimum cost of achieving the utility level $\tilde{u}^{j}$ given international prices $p$ and aggregate pollution level $k$. Utility depends positively on consumption $x$ and negatively on emissions $k$. The expenditure function is concave and linear homogeneous in prices and is assumed to be twice continuously differentiable. By Shephard's Lemma, the Hicksian compensated demand vector is represented by $e_{p}^{j}$ and the consumer's marginal willingness to pay for pollution abatement is given by $e_{k}^{j}$, while $e_{u}^{j}>0$ denotes the inverse of the marginal utility of income. An increase in the level of any pollutant would require an increase in consumption to compensate the consumer for the disutility from pollution; thus, expenditure is increasing in $k$, implying $e_{k}^{j}>0$. The matrix $e_{p p}^{j}$ gives the consumption substitution effects and is negative semidefinite. The sensitivity of (compensated) consumption demand to pollution emissions is given by $e_{p k}^{j}{ }^{6}$ Additionally, we follow most of the literature (e.g., Keen and Kotsogiannis 2014; Antoniou et al. 2019) in assuming that the marginal utility of income is independent of prices, i.e., $e_{p u}^{j}=0 .^{7,8}$

Each country imposes sector specific emission taxes, denoted by the vector $s^{j} .{ }^{9}$ In each sector, firms maximise revenue by choosing a feasible combination of emission $\left(z^{j}\right)$ and output $\left(y^{j}\right)$ for a given technology $t^{j}$ and vector of endowments $\left(v^{j}\right)$, resulting in the revenue function:

$$
g^{j}\left(p, s^{j}, v^{j}\right)=\operatorname{Max}_{y, z}\left\{p^{\prime} y^{j}-s^{j \prime} z^{j}: y^{j}, z^{j} \epsilon t^{j}\left(v^{j}\right)\right\} .
$$

The revenue function is convex, homogeneous of degree one in prices and emission taxes and is assumed to be twice continuously differentiable. ${ }^{10}$ Hotelling's Lemma implies that the price derivatives of the revenue function give the vector of the net supplies of tradable goods $y^{j}=g_{p}^{j}$. By the envelope property $z^{j}=-g_{s}^{j}$, i.e. the vector of emissions equals the marginal abatement costs. ${ }^{11}$ Thus, totally differentiating $z^{j}$, we obtain the effect of the environmental policy on emission:

$$
d z^{j}=-\left(g_{s s}^{j} d s^{j}+g_{s p}^{j} d p^{j}\right)
$$

\footnotetext{
6 The elements of the $e_{p k}^{j}$ vector can be positive or negative depending on whether the good's (compensated) demands and pollution are complements or substitutes in consumption.

7 This assumption can be relaxed without altering the qualitative nature of the results, but at the cost of greater analytical complexity.

8 The assumptions regarding the expenditure function are consistent with a quasi-linear utility function of the form $U\left(x_{1}, x_{l}, z\right)=x_{1}+V\left(x_{l}, z\right)$ with $\imath \in[2, Q]$ and where $x_{1}$ represents the numeraire good.

9 The first tradable good is assumed to be the numeraire which, as is standard in the literature, will also not be taxed.

${ }^{10}$ For the properties of the revenue function see Dixit and Norman (1980), Woodland (1982) and Copeland (1994).

11 This, in turn, implies that global pollution can be rewritten as $k=-\sum_{j=1}^{N} i^{\prime} g_{s}^{j}$.
} 
where the first term on the right-hand-side represents the environmental policy's direct effect on production and is positive definite. The second term reflects the indirect effect arising from the impact of changes in prices on production; the sign of the elements of this matrix depends on the pollution intensity of production. ${ }^{12}$ Thus, by Eqs. (1) and (4) the change in global pollution is given by:

$$
d k=-\sum_{j=1}^{N} i^{\prime}\left(g_{s s}^{j} d s^{j}+g_{s p}^{j} d p\right)=-\sum_{j=1}^{N}\left(i^{\prime} g_{s s}^{j} d s^{j}\right)-\sum_{j=1}^{N}\left(i^{\prime} g_{s p}^{j} d p\right) .
$$

It is assumed that the emission tax revenues are returned to the consumer in a lump-sum fashion. Thus, the economy's aggregate budget constraint is given by:

$$
e^{j}\left(u^{j}, p, k\right)=g^{j}\left(p, s^{j}\right)+s^{j \prime} z^{j} .
$$

The market clearing condition requires that the sum of excess demands across the world should be equal to zero:

$$
\sum_{j=1}^{N} m^{j}=\sum_{j=1}^{N}\left\{e_{p}^{j}-g_{p}^{j}\right\}=0 .
$$

Equations (1), (6), and (7) determine the economy's equilibrium. The latter will be characterised by $Q+N$ unknowns, namely $Q-1$ relative prices, $N$ utility levels and the aggregate pollution level. Correspondingly, we have $Q+N+1$ equations of which one can be dropped by Walras' Law.

\section{Optimal Environmental Policy}

In this section, we analyse environmental policy under different scenarios.

\subsection{Optimal policy in the absence of environmental agreements}

We start by considering the case in which the emission taxes are set unilaterally or in a fully multilateral cooperative setting in the absence of a IEA. Although the results are well established in the literature, ${ }^{13}$ they will offer a useful benchmark for the analysis of international environmental agreements.

By differentiating the market clearing condition (7), and making use of (5), we can identify the effect of the environmental policy on international prices:

\footnotetext{
12 Copeland (1994) defines a good to be pollution intensive if $\partial z_{i} / \partial p_{i}>0$. An increase in the price of good $i$ will result in an increase in its output by drawing resources away from the rest of the economy. If, at the margin, the expanding part of the economy produces more pollution than the contracting part, the sector producing good $i$ is pollution intensive. See also Neary (2006).

${ }^{13}$ See, e.g., Markusen (1975), Keen and Kotsogiannis (2014), Tsakiris et al. (2014), Tsakiris et al. (2017), Vlassis (2013), Kotsogiannis and Woodland (2013).
} 


$$
d p=\Lambda^{-1} \sum_{j=1}^{N}\left\{\left[g_{p s}^{j \prime}+\left(\sum_{j=1}^{N} e_{p k}^{j}\right) i^{\prime} g_{s s}^{j}\right] d s^{j}\right\}
$$

where

$$
\Lambda=\sum_{j=1}^{N}\left[e_{p p}^{j \prime}-g_{p p}^{j \prime}-\left(\sum_{j=1}^{N} e_{p k}^{j}\right) i^{\prime} g_{s p}^{j}\right]
$$

is the pollution augmented world net substitution matrix which is assumed to be of full rank and invertible.

Equation (8) reflects the fact that changes in environmental policy affect prices via changes in both production levels, $\left(g_{p s}^{j \prime} d s^{j}\right)$, and, given the latter's effect on pollution, consumption levels, $\left(\sum_{j=1}^{N} e_{p k}^{j}\right) i^{\prime} g_{s s}^{j} d s$.

To evaluate the impact of the environmental policy on welfare, we totally differentiate the budget constraint in (6) to obtain

$$
e_{u}^{j} d u^{j}=\left[-m^{j \prime}-s^{j^{\prime}} g_{s p}^{j}+e_{k}^{j} i^{\prime}\left(\sum_{v=1}^{N} g_{s p}^{v}\right)\right] d p-s^{j^{\prime}} g_{s s}^{j} d s^{j}+e_{k}^{j} i^{\prime} \sum_{\nu=1}^{N}\left(g_{s s}^{v} d s^{\nu}\right) .
$$

The three terms on the right-hand-side of Eq. (10) indicate, respectively, that a change in environmental policy affects a country's welfare via three main channels: (1) "terms of trade", through a direct impact on on trade flows $\left(-m^{j} d p\right)$, and indirect effects on government revenue $\left(-s^{j^{\prime}} g_{s p}^{j} d p\right)$ and global pollution $\left(e_{k}^{j} i^{\prime} \sum_{v=1}^{N} g_{s p}^{v}\right)$; (2) government revenue $\left(s^{j \prime} g_{s s}^{j} d s^{j}\right)$, and (3) global pollution, $\left(e_{k}^{j} i^{\prime} \sum_{v=1}^{N}\left(g_{s s}^{v} d s^{v}\right)\right)$.

In order to derive the optimal non-cooperative environmental policy, we substitute (8) into (10) to rewrite the changes in the welfare function as

$$
\begin{gathered}
-m^{j} \sum_{\nu=1}^{N}\left(\mu^{\nu} d s^{\nu}\right) \\
e_{u}^{j} d u^{j}=-s^{j \prime}\left(g_{s p}^{j} \sum_{\nu=1}^{N}\left(\mu^{\nu} d s^{\nu}\right)+g_{s s}^{j} d s^{j}\right) \\
+e_{k}^{j} i^{\prime} \sum_{\nu=1}^{N}\left(g_{s s}^{v}+\left(\sum_{\nu=1}^{N} g_{s p}^{\nu}\right) \mu^{\nu}\right) d s^{\nu},
\end{gathered}
$$

where

$$
\mu^{\nu}=\Lambda^{-1}\left[g_{p s}^{\nu}+\left(\sum_{j=1}^{N} e_{p k}^{j}\right) i^{\prime} g_{s s}^{v}\right]
$$

from which the optimal unilateral environmental policy is 


$$
s^{j \prime}=e_{k}^{j} i^{\prime}-\Omega^{j},
$$

where $\Omega^{j}=\left[m^{j}-e_{k}^{j}\left(\sum_{l=1, l \neq j}^{N} g_{s p}^{l}\right)\right] \mu^{j}\left(g_{s s}^{j}+g_{s p}^{j} \mu^{j}\right)^{-1} \cdot{ }^{14}$ Consistent with Keen and Kotsogiannis (2014), Tsakiris et al. (2014) and Markusen (1975), the optimal unilateral emission taxes account for the difference between the consumer's marginal willingness to pay for pollution abatement, $e_{k}^{j} i^{\prime}$, and the policy's direct and indirect effect on the terms of trade through imports/exports $m^{j}$ and rest of the world emissions $e_{k}^{j}\left(\sum_{l=1, l \neq j}^{N} i^{\prime} g_{s p}^{j}\right)$. The term $\Omega^{j}$ dictates whether the Nash equilibrium emission tax is larger or smaller than the consumer's marginal willingness to pay for pollution abatement $e_{k}^{j}{ }^{15} \mathrm{~A}$ key difference with the extant literature is that, due to the fact that there is only one available policy instrument to address two distortions, the terms of trade and emission leakage effects are weighted by the direct effect of the policy on emission levels $g_{s s}^{j}$ and its indirect effect through prices $g_{s p}^{j}{ }^{16}$

The importance of the role of the terms of trade in shaping the policy can be further highlighted by considering the small open economy case in which changes in environmental policy would not affect prices and hence the terms of trade. In addition, changes in policy in one country would also not have any international leakage effects affecting production and hence pollution in other countries. In this case, it is then easy to show that the non-cooperative equilibrium would require each country to equate its environmental tax to its consumers' willingness to pay for pollution abatement, i.e. $s^{j \prime}=e_{k}^{j} i^{\prime}$.

Under full cooperation, countries set environmental policy by maximising their joint welfare function. As always under cooperation, countries can choose a uniform (i.e. common) policy or country-specific taxes. In the case of global cooperation, the two coincide. To see this, for the case of country-specific taxes, we use the market clearing condition in (7) together with the sum of the individual countries' welfare to write the change in world welfare as: ${ }^{17}$

$\overline{14}$ To see how Eq. (12) is obtained, it proves useful to re-write Eq. (11) as:

$$
\begin{aligned}
e_{u}^{j} d u^{j}= & {\left[-m^{j} \mu^{j}-s^{j}\left(g_{s p}^{j} \mu^{j}+g_{s s}^{j}\right)+e_{k}^{j} i^{\prime}\left(g_{s s}^{j}+\left(\sum_{v=1}^{N} g_{s p}^{v}\right) \mu^{j}\right)\right] d s^{j} } \\
+ & +\sum_{l=1, l \neq j}^{N}\left[-m^{j} \mu^{l}-s^{j}\left(g_{s p}^{j}\left(\mu^{l} d s^{l}\right)\right)+e_{k}^{j} i^{\prime}\left(g_{s s}^{l}+\left(\sum_{v=1}^{N} g_{s p}^{v}\right) \mu^{l}\right)\right] d s^{l} .
\end{aligned}
$$

15 Given the generality of our model, it is not possible to determine the sign of $\Omega^{j}$. To do so would require considering special cases involving a reduction of the model's dimensionality. For instance, in a $2 \mathrm{X} 2$ case, if country 1 were a net importer, it would set its optimal tax lower than the consumers' marginal willingness to pay for pollution abatement if: (1) $\mu^{1}>0$ (which requires substitutability in consumption between compensated demand and clean environment, i.e. $e_{p k}<0$ and so $e_{p k}^{1}+e_{p k}^{2}<0$, as well as that production is pollution intensive, i.e. $g_{s p}^{1}<0$, and $g_{s s}^{1}>0$ and (2) the direct effects of a tax on emissions exceed the indirect effects through a change in prices, i.e. $g_{s s}^{1}+g_{s p}^{1} \mu^{1}>0$.

16 Our result is also consistent with the non-cooperative Nash equilibrium carbon permit price obtained by Copeland (1994) which equals the marginal willingness to pay for pollution abatement to an indirect terms of trade effect. Again, the key difference is the term reflecting the impact of policy induced price changes on global emissions which arises in our model as a result of the absence of trade policy to target trade related distortions. See Markusen (1975) for a discussion of corrective taxation in the case of a single policy instrument to deal with several distortions simultaneously.

17 Implicitly, behind this is the existence of lump sum transfers between countries with the welfare of each country being equally weighted. 


$$
\sum_{j=1}^{N} e_{u}^{j} d u^{j}=\sum_{j=1}^{N}\left\{\left[\left(\sum_{j=1}^{N} e_{k}^{j} i^{\prime}\right)-s^{j^{\prime}}\right] \delta^{j} d s^{j}\right\},
$$

where $\delta^{j}=\left[g_{s s}^{j}+\left(\sum_{j=1}^{N} g_{s p}^{j}\right) \mu^{j}\right]$. Then, for $\delta \neq 0$, the optimal cooperative environmental taxes are all equal to:

$$
s^{\text {coop }}=\left(\sum_{j=1}^{N} e_{k}^{j} i\right) .
$$

which implies that the cooperative second best optimal environmental policy should be uniform across all countries and equal to the cumulative (global) marginal damage caused by an additional unit of emission. Since the marginal damage from emissions is the same irrespective of the sector and country that generate them, each country sets the same emission tax across all the sectors. Given free trade, the second best fully cooperative environmental tax coincides with the first best policy (e.g. Keen and Kotsogiannis 2014; Kotsogiannis and Woodland 2013; Vlassis 2013). This is because under global cooperation and free trade, the optimal environmental tax takes trade distortions (created by the impact of environmental policies on world prices) fully into account, while the implicit international transfers deal with distributional concerns. The full internalisation of the terms of trade effects then implies that the cooperative solution corresponds to that which would emerge if all countries were small open economies - in which case no terms of trade effects would be present.

In Sect. 3.3 we shall highlight the differences between the optimal policy in the noncooperative and cooperative equilibria. Before doing so, we now proceed to examine environmental policy within international environmental agreements.

\subsection{Optimal Environmental Policy within an International Environmental Agreement}

We now consider the case in which a subset of countries signs an environmental agreement with the aim of coordinating their environmental policy so as to maximise their joint welfare. We shall examine two cases: in the first, the participating countries set countryspecific environmental policies; in the second, they choose a common tax rate resulting in full policy harmonisation.

Denoting the participating and non-participating countries by the superscripts $h$ and $f$ respectively, the policy induced changes in the aggregate welfare of the participating countries are given by: ${ }^{18}$

\footnotetext{
${ }^{18}$ The policy's welfare effects of the non-participating countries and their optimal environmental policy are as described by Eqs. (11) and (12).
} 


$$
\begin{aligned}
& \sum_{h=1, h \neq f}^{N}\left\{\left(-m^{h}\right) \sum_{j=1}^{N}\left(\mu^{j} d s^{j}\right)\right\} \\
\sum_{h=1, h \neq f}^{N} e_{u}^{h} d u^{h}= & -\sum_{h=1, h \neq f}^{N}\left\{s^{h \prime}\left(g_{s s}^{h} d s^{h}+g_{s p}^{h} \sum_{j=1}^{N}\left(\mu^{j} d s^{j}\right)\right)\right\} \\
& +\sum_{h=1, h \neq f}^{N}\left\{e_{k}^{h i^{\prime}} \sum_{j=1}^{N}\left\{\left(g_{s s}^{j}+\left(\sum_{j=1}^{N} g_{s p}^{j}\right) \mu^{j}\right) d s^{j}\right\}\right\},
\end{aligned}
$$

where the three terms on the right-hand-side reflect, respectively: (1) the change in the participating countries' terms of trade; (2) the impact of policy on tax revenues from emission-due to changes in the production, and thus emissions, of the participating countries (directly as a result of the changes in environmental taxes and indirectly through the terms of trade); and (3) the cumulative impact of the policy on world emission leakage weighted by the participating countries marginal willingness to pay for pollution abatement.

If the participating countries maximise their joint welfare with respect to country-specific tax rates, the optimal tax $s^{h^{*}}$ they will set for the typical participating country $h^{*}$ will be:

$$
s^{h^{*}}=\sum_{h=1, h \neq f}^{N} e_{k}^{h} i^{\prime}-\Phi,
$$

where $\Phi=\left\{\sum_{1}\left(\sum_{h=1, h \neq f}^{N} m^{h}\right)+\left(\sum_{h=1, h \neq h^{*}, f}^{N} s^{h} g_{s p}^{h}\right)-\left(\sum_{h=1, h \neq f}^{N} e_{k}^{h} i^{\prime}\right)\left(\sum_{h=1, j \neq h^{*}}^{N} g_{s p}^{j}\right)\right\}$ $\mu^{h^{*}}\left(g_{s s}^{h^{*}}+g_{s p}^{h^{*}} \mu^{h^{*}}\right)^{-1}$.

Proposition 1 The second best country-specific optimal environmental policy of an international environmental agreement will reflect the participating countries' cumulative consumers' marginal willingness to pay for pollution abatement, their cumulative terms of trade effects, as well as the pollution externalities arising from the change in production in both participating and non-participating countries.

Intuitively, maximisation of the joint welfare of the participating countries implies that for each one of them the environmental tax should reflect the difference between the signatories' cumulative marginal damage from emissions and the country-specific effects of the tax on terms of trade and emission leakages. Specifically, the term $\left(\sum_{h=1, h \neq f}^{N} m^{h}\right)$ reflects the policy's effect on the participating countries' terms of trade. The term $\left(\sum_{h=1, h \neq h^{*}, f}^{N} s^{h} g_{s p}^{h}\right)$ captures the internalisation of the policy externalities between the participating countries. This term has an interesting policy implication: it suggests that, as a result of the policy externality, a strict environmental policy by one member is compatible with 'softer' environmental standards in other participating countries. Finally, the term $\left(\sum_{h=1, h \neq f}^{N} e_{k}^{h} i^{\prime}\right)\left(\sum_{j=1, j \neq h^{*}}^{N} g_{s p}^{j}\right)$ reflects the internalisation of the price and, consequently, production externalities arising from all other countries. The discrepancy between the participating countries' country-specific taxes reflects the intercountry differences in the direct and indirect impact (through changes in prices and production) of the tax on a country's emissions, $\mu^{h^{*}}\left(g_{s s}^{h^{*}}+g_{s p}^{h^{*}} \mu^{h^{*}}\right)^{-1}$. This highlights even further the fact that participating countries can set different levels of environmental taxes to address common targets whilst accommodating for country specific characteristics - as is, for example, the case within the European Union where all countries participate in the EU Emissions 
Trading System whilst retaining country specific environmental policy/targets. Similar to what we discussed in the previous section, in the case in which all signatories (and the resulting 'environmental union') were small open economies, the absence of terms of trade effects would imply that the optimal policy would entail a cooperative tax rate equal to the signatories' consumers willingness to pay for pollution abatement, i.e: $s^{h}=\left(\sum_{h=1, h \neq f}^{N} e_{k}^{h} i^{\prime}\right)$.

If policy coordination results in full perfect tax harmonization among the signatories, i.e. when they maximise their joint welfare with respect to a common tax rate, the optimal environmental tax will be given by:

$$
s^{h^{*}}=\sum_{h=1, h \neq f}^{N} e_{k}^{h} i^{\prime}-\Psi,
$$

$\Psi=\left[\left(\sum_{h=1, h \neq f}^{N} m^{h}\right)-\left(\sum_{h=1, h \neq f}^{N} e_{k}^{h} i^{\prime}\right)\left(\sum_{f=1, f \neq h}^{N} g_{s p}^{f}\right)\right]\left(\mu^{h^{*}}\right)\left(\sum_{h=1, h \neq f}^{N}\left(g_{s s}^{h}+g_{s p}^{h} \mu^{h}\right)^{-1}\right)^{\mathrm{r}}$. As is clear from (17), the uniform tax depends on the participating countries' marginal willingness to pay for pollution reduction $\left(\sum_{h=1, h \neq f}^{N} e_{k}^{h} i^{\prime}\right)$, their terms of trade effects $\left(\sum_{h=1, h \neq f}^{N} m^{h}\right)$, and the externality of the non-participating countries weighted by the participating countries marginal damage $\left(\sum_{h=1, h \neq f}^{N} e_{k}^{h} i^{\prime}\right)\left(\sum_{f=1, f \neq h}^{N} g_{s p}^{f}\right)$.

\subsection{Comparison of optimal environmental policies}

The differences between the optimal unilateral policy in Eq. (12) and the multilateral policies in Eqs. (14), (16) and (17) reflect the fact that, contrary to the former, multilateral policies do not simply take into account a country's own consumer marginal damage from emissions, but also internalise the damage to the consumers of all the countries participating in the agreement. However, whilst in the multilateral case full coordination results in the internalisation of all the externalities, policy coordination between the subset of countries that form an environmental agreement only internalises the externalities among member countries. In addition, the difference between the country-specific and the fully harmonised optimal environmental policy within an IEA — given respectively by Eqs. (16) and (17) - reflects the fact that the former does not only internalise the intra-agreement externalities but also takes into account country-specific characteristics.

As highlighted in the previous sections, when terms of trade effects are absent, as in the case in which countries (or the 'environmental union') are price takers, the optimal policy always corresponds to the relevant consumers' marginal willingness to pay for pollution abatement.

Given that in the case of full multilateral cooperation analysed in Sect. 3, the cumulative impact of the externality has been fully internalised, there are no distributional effects across countries through the terms-of-trade channel. Instead, as is the case of unilateral environmental policies, partial multilateral cooperation affects the terms-of-trade, stimulating trade creation and trade diversion effects. An interesting implication of this is that the terms of trade effects may generate incentives or disincentives for some countries to join an environmental agreement, or to adopt environmental policies, to overcome the non availability of trade policy instruments in order to correct the terms-of-trade distortion. In addition, in the case of partial cooperation, in setting their optimal environmental policy, the 
IEA participants' take into account the direct impact of the policy on their emission as well as on the emissions resulting from changes in production in the rest of the world.

The effects of the different policy scenarios on welfare levels are not easy to quantify within this framework as a result of its high dimensionality. However, given the higher degree of internalisation of the policy externalities that characterises it, the multilateral setting ought to be dominating from a welfare point of view. ${ }^{19}$ In reality, we observe the prevalence of REAs over global cooperation. This may reflect the higher complexity of global coordination arising, for instance, from the conflict of interest among many and very heterogeneous countries. Clearly, however, the size of the agreement plays an important role in determining the level of the optimal environmental tax as it affects the cumulative marginal damage and the terms of trade effects. It also magnifies the externalities arising from the non-participating countries' production distortions. Whether an increase in the number of participating countries results in an increase in the optimal emission tax level will depend on the balance of those effects.

\section{Welfare Effects of an IEA on Participating and Non-participating Countries}

In this section, we examine the welfare effects of an IEA's changes in policy on participating and non-participating countries.

Rewriting the market clearing condition in Eq. (7) as:

$$
-\sum_{h=1, h \neq f}^{N} m^{h}=\sum_{f=1, f \neq h}^{N} m^{f},
$$

and combining it with Eqs. (15) and (11), we obtain

$$
\begin{gathered}
\sum_{h=1, h \neq f}^{N} e_{u}^{h} d u^{h}= \\
+\sum_{j=1}^{N}\left\{\left(\sum_{j=1}^{N} e_{k}^{j} i^{\prime}-s^{j \prime}\right)\left(e_{u}^{f} d u^{f}\right\}\right. \\
\left.\left.g_{s s}^{j} d s^{j}+g_{s p}^{j} \sum_{j=1}^{N} \mu^{j} d s^{j}\right)\right\}
\end{gathered}
$$

Equation (19) states that a change in the participating countries' environmental policy will affect their aggregate welfare through terms of trade (via changes in international prices) and emission leakage effects. The first terms on the right-hand-side of the equation arises from the direct terms of trade effects of the IEA's policy change and implies that there is a negative relationship between the change in welfare of participating and non-participating countries. $^{20}$ This negative relationship has not been highlighted by the existing trade/environmental literature that has only considered the case of full cooperation within global

\footnotetext{
19 Tsakiris et al. (2017) analyse the issue of efficiency of the non-cooperative versus the cooperative equilibrium of environmental policy, in a two country model with capital mobility. They conclude that in the presence of cross-border pollution, the non-cooperative settings of the available instruments is always inefficient relative to the cooperative ones.

20 To see this, isolate the terms of trade term in Eq. (11) and substitute it for all the non-participating countries in (18). The resulting expression can then be substituted for the participating countries' terms of trade in (15) to get (19).
} 
environmental agreements. ${ }^{21}$ However, the second term of (19) further implies that the overall effects of a change in policy within an IEA will not result in a zero-sum welfare outcome for the "world" as a whole; in other words, the magnitude of the welfare effects of the IEA's policy change on the participating countries will typically not equal that on the non participating ones. The reason for this it that the IEA's policy is set without internalising its effects on the non participating countries and hence on the cumulative world marginal damage; such internalisation can only occur in the full multilateral cooperative case where $s^{\text {coop }}=\left(\sum_{j=1}^{N} e_{k}^{j} i\right)$.

To emphasise:

Proposition 2 There exists a negative relationship, arising from the terms of trade effects of the IEA's policy, between the participating and the non-participating countries' change in welfare. Equations (16) and (17) imply, however, that the overall effects of a change in policy within an IEA will not result in a zero-sum welfare outcome for the "world" as a whole.

To gain further insights into the nature of the relationship between the welfare effects of the IEA on participating and non participating countries, it is useful to examine a special case that reduces the dimensionality of the model without altering its essential features. Specifically, we consider a three country two good framework in which all countries produce a clean good (used as the numeraire) and a polluting good. ${ }^{22}$ Country 1 and 2 sign an environmental agreement and country 3 is assumed, without loss of generality, to be policy inactive (i.e. $s^{3}=d s^{3}=0$ ). In this case, it is straightforward to show that the change in welfare of the participating countries in Eq. (19) can be written as

$$
\begin{aligned}
e_{u}^{1} d u^{1}+ & e_{u}^{2} d u^{2} \\
= & +\left\{\left(\sum_{i=1}^{3} e_{k}^{i}-s^{1}\right)\left(\left(g_{s s}^{1}+g_{s p}^{1} \Xi^{-1} g_{p s}^{1}\right)\right)+\left(\sum_{i=1}^{3} e_{k}^{i}-s^{2}\right) g_{s p}^{2} \Xi^{-1} g_{p s}^{1}+\left(\sum_{i=1}^{3} e_{k}^{i}\right) g_{s p}^{3} \Xi^{-1} g_{p s}^{1}\right\} d s^{1} \\
& +\left\{\left(\sum_{i=1}^{3} e_{k}^{i}-s^{2}\right)\left(g_{s s}^{2}+g_{s p}^{2} \Xi^{-1} g_{p s}^{2}\right)+\left(\sum_{i=1}^{3} e_{k}^{i}-s^{1}\right) g_{s p}^{1} \Xi^{-1} g_{p s}^{2}+\left(\sum_{i=1}^{3} e_{k}^{i}\right) g_{s p}^{3} \Xi^{-1} g_{p s}^{2}\right\} d s^{2},
\end{aligned}
$$

where $\Xi=\sum_{i=1}^{3}\left(e_{p p}^{i}-g_{p p}^{i}\right)<0$ and

$$
\begin{aligned}
e_{u}^{3} d u^{3}= & -\left\{m^{3}-e_{k}^{3}\left(g_{s p}^{1}+g_{s p}^{2}+g_{s p}^{3}\right)\right\} \Xi^{-1} g_{p s}^{1} d s^{1}+e_{k}^{3} g_{s s}^{1} d s^{1} \\
& -\left\{m^{3}-e_{k}^{3}\left(g_{s p}^{1}+g_{s p}^{2}+g_{s p}^{3}\right)\right\} \Xi^{-1} g_{p s}^{2} d s^{2}+e_{k}^{3} g_{s s}^{2} d s^{2}
\end{aligned}
$$

is the change in welfare of the non-participating country.

\footnotetext{
${ }^{21}$ Since the negative relationship between the change in welfare of participating and non-participating countries arises from the terms of trade effects of the change in policy, it would not emerge in the case of price taking countries; in this instance, Eq. (19) would be $\sum_{h=1, h \neq f}^{N} e_{u}^{h} d u^{h}=\left\{\left(\sum_{h=1, h \neq f}^{N} e_{k}^{h} i^{\prime}\right)-s^{h \prime}\right\} \sum_{h=1, h \neq f}^{N}\left(g_{s s}^{h} d s^{h}\right)+\sum_{h=1, h \neq f}^{N} e_{k}^{h} i^{\prime} \sum_{f=1, f \neq h}^{N}\left(g_{s s}^{f} d s^{f}\right)$ which implies that the participating countries' change in welfare would depend on their policy's effect on their revenues from environmental taxation, and their consumers willingness to pay for global emission abatement.
}

${ }^{22}$ The $3 \times 2$ framework is common within the customs union literature (e.g. Vanek 1965). 
As in the general case, Eq. (20) implies a negative relationship between the welfare changes of the participating and non-participating countries and reflects the same qualitative channels through which the policy affects welfare changes: the change in the participating countries' emission taxes will affect the welfare of the non-participating ones through their impact on terms of trade as well as their intra- and inter-bloc emission leakage effects. However, it is now easier to gain understanding of the direction of these welfare changes. As discussed earlier, it has to be the case that $\sum_{i=1}^{3} e_{k}^{i}-s^{j}>0, j=1,2$. Then, as can be seen from the second and third terms on the right-hand-side of Eq. (20), a stricter environmental policy by the participating countries (i.e., $d s^{1}, d s^{2}>0$ ) will: (1) increase their welfare via its direct and indirect effects on own emission (since the magnitude of the direct effects dominates that of the indirect effects); (2) decrease their welfare via the terms-of-trade induced intra-IEA leakage effect; and (3) decrease their welfare via a termsof-trade induced leakage effect on the non-participating country. If the direct effects are sufficiently stronger than the indirect effects of the change in policy, the second and third term on the right-hand-side of the equation are positive. In this instance, a sufficient condition for the change in welfare of the participating countries to be positive is that $e_{u}^{3} d u^{3}<0$. As can be seen from Eq. (21), this condition will hold for a net importing country if (1) the direct terms-of-trade induced effects dominate the indirect ones, and (2) the direct and indirect effects from terms-of-trade changes dominate the positive global pollution externality form the IEA. An implication of the above analysis is then that the policy's terms of trade effect on a non-participating country will be affected by the country's initial trade status. ${ }^{23}$

In general, our results suggest that an environmental policy reform that is Pareto improving for the IEA participating countries can reduce the level of welfare in the non-participating countries due to the trade creation and trade diversion effects of the policy. This implies that the terms-of-trade effects of environmental policy are an important channel affecting the incentives of countries to join an environmental agreement and can weaken the pollution haven effect. Our findings are in line with Al Khourdajie and Finus (2020) who show, in a game theoretic setup, that the manipulation of the terms of trade can lead to the formation of larger stable environmental agreements. This line of argument can contribute to explain the discrepancy [e.g. as highlighted by Marrouch and Chaudhuri (2016)] between the optimal size of environmental agreements predicted by the standard game theoretic literature and the much larger size observed in reality as with the Kyoto Protocol of 1997 and the Paris Agreement of 2015 that were signed by 37 and 196 countries, respectively.

\section{Conclusion}

This paper has developed a $N$-country $Q$-goods general equilibrium framework to analyse unilateral and cooperative optimal environmental policies within an environmental agreement. The analysis highlights the importance of the terms of trade, via trade creation and trade diversion effects, for the characterisation of the optimal environmental policy and its welfare effects on participating and non-participating countries. The potential gains from increased trade may offset the increased costs of higher environmental taxes within an agreement. It is also theoretically possible that even when resulting in a global increase in

\footnotetext{
23 It is possible to show that a sufficient condition for the IEA's policy to be welfare improving for an individual participating country is that the direct effects of the policy dominate the indirect effects arising from terms-of-trade adjustments.
} 
welfare, an IEA may lead to an overall increase in pollution, depending on the production structure and relative pollution intensity of participating and non-participating countries.

A key finding of this paper is that the terms of trade effects of the environmental policy give rise to a negative relationship between the welfare changes of the participating and the non-participating countries - even in the absence of zero sum welfare gains. An interesting implication of the analysis is then that countries may be willing to participate in an IEA as the terms of trade channel can contribute to mitigate the typical loss of comparative advantage resulting from stricter environmental regulation.

Acknowledgements We are grateful to two anonymous referees and to the Editor of the Journal for very constructive suggestions. We would also like to thank participants at the EAEAE annual conference in Athens and at the Scottish Economic Society annual conference in Perth. The usual disclaimer applies.

Open Access This article is licensed under a Creative Commons Attribution 4.0 International License, which permits use, sharing, adaptation, distribution and reproduction in any medium or format, as long as you give appropriate credit to the original author(s) and the source, provide a link to the Creative Commons licence, and indicate if changes were made. The images or other third party material in this article are included in the article's Creative Commons licence, unless indicated otherwise in a credit line to the material. If material is not included in the article's Creative Commons licence and your intended use is not permitted by statutory regulation or exceeds the permitted use, you will need to obtain permission directly from the copyright holder. To view a copy of this licence, visit http://creativecommons.org/licenses/by/4.0/.

\section{References}

Al Khourdajie A, Finus M (2020) Measures to enhance the effectiveness of international climate agreements: the case of border carbon adjustments. European Economic Review 124:103405 (Virtual Special Section on: The Interface between Structural Micro and Macroeconomics; Edited by Z. Eckstein, M.P. Keane, R. Rogerson and R.M. Sauer)

Antoniou F, Hatzipanayotou P, Michael M, Tsakiris N (2019) On the principles of commodity taxation under interregional externalities. University of Cyprus Working Papers in Economics 03-2019, University of Cyprus Department of Economics

Barrett S (1994) Self-enforcing international environmental agreements. Oxf Econ Pap 46:878-894

Barrett S (1995) Trade restrictions in international environmental agreements. London Business School, London

Barrett S (1997) The strategy of trade sanctions in international environmental agreements. Resour Energy Econ 19:345-361

Baylis K, Fullerton D, Karney D (2014) Negative leakage. J Assoc Environ Resour Econ 1(1):51-73

Carraro C, Eyckmans J, Finus M (2006) Optimal transfers and participation decisions in international environmental agreements. Rev Int Organ 1(4):379-396

Chua S (2003) Does tighter environmental policy lead to a comparative advantage in less polluting goods? Oxf Econ Pap 55(1):25-35

Copeland RB (1994) International trade and the environment: policy reform in a polluted small open economy. J Environ Econ Manag 26(1):44-65

Dixit A, Norman V (1980) The theory of international trade. Cambridge University Press, Cambridge

Dong D, Zhao X (2009) International environmental agreement formation and trade. Asia Pac J Account Econ 16(3):339-356

Eichner T, Pethig R (2013) Self-enforcing environmental agreements and international trade. J Publ Econ 102:37-50

Eichner T, Pethig R (2015) Self-enforcing international environmental agreements and trade: taxes versus caps. Oxf Econ Pap 67(4):897-917

Finus M, Rundshagen B (2000) Strategic links between environmental and trade policies if plant location is endogenous. University of Hagen. Working paper no. 283

Finus M (2003) Stability and design of international environmental agreements: the case of transboundary pollution. In: Folmer H, Titenberg T (eds) The international yearbook of environmental and resource economics 2003-04. Edward, Elgard, pp 82-158 
Finus M, Caparros A (2015) Handbook on game theory and international environmental cooperation: essential readings. The international library of critical writings in economics series, Edward Elgar Publishing Ltd, Cheltenham, UK

Hatzipanayotou P, Lahiri S, Micheal M (2008) Cross-border pollution, terms of trade, and welfare. Environ Resource Econ 41:327-345

Hoel M (1992) International environmental conventions: the case of uniform reductions of emissions. Environ Resour Econ 2:141-159

Hoel M, Schneider M (1997) Incentives to participate in an international environmental agreement. Environ Resour Econ 9(2):153-170

Keen M, Kotsogiannis C (2014) Coordinating climate and trade policies: pareto efficiency and the role of border tax adjustments. J Int Econ 94(1):119-128

Kotsogiannis C, Woodland A (2013) Climate and international trade policies when emissions affect production possibilities. J Environ Econ Manag 66(2):166-184

Krutilla K (1991) Environmental regulation in an open economy. J Energy Econ Manag 20:127-142

Markusen JR (1975) International externalities and optimal tax structures. J Int Econ 5(1):15-29

Marrouch W, Chaudhuri AR (2016) International environmental agreements: doomed to fail or destined to succeed? A review of the literature. Int Rev Environ Resour Econ 9(3-4):245-319

Michael M, Hatzipanayotou P (2013) Pollution and reforms of domestic and trade taxes towards uniformity. Int Tax Publ Finance 20(5):753-768

Mitchell RB (2003) International environmental agreements: a survey of their features, formation, and effects. Annu Rev Environ Resour 28:429-461

Neary J (2006) International trade and the environment: theoretical and policy linkages. Environ Resour Econ 33(1):95-118

Tsakiris N, Hatzipanayotou P, Micheal M (2014) Asymmetric tax policy responses in large economies with cross-border pollution. Environ Resour Econ 58(4):563-578

Tsakiris N, Hatzipanayotou P, Micheal M (2017) Welfare ranking of environmental policies in the presence of capital mobility and cross-border pollution. South Econ J 84(1):317-336

Turunen-Red A, Woodland A (2004) Multilateral reforms of trade and environmental policy. Rev Int Econ 12(3):321-336

Vanek J (1965) General equilibrium of international discrimination. Harvard University Press, Cambridge

Vlassis N (2013) The welfare consequences of pollution tax harmonisation. Environ Resour Econ 56(2):227-328

Woodland A (1982) International trade and resource allocation. North-Holland, Amsterdam

Publisher's Note Springer Nature remains neutral with regard to jurisdictional claims in published maps and institutional affiliations. 